\title{
Particulate Matter Exposure in Cars Is Associated with Cardiovascular Effects in Healthy Young Men
}

\author{
Michael Riediker, Wayne E. Cascio, Thomas R. Griggs, Margaret C. Herbst, Philip A. Bromberg, Lucas Neas, \\ Ronald W. Williams, and Robert B. Devlin \\ Center for Environmental Medicine, Asthma and Lung Biology, School of Medicine; Division of Cardiology, School of Medicine, \\ University of North Carolina at Chapel Hill; North Carolina State Highway Patrol, Raleigh; U.S. Environmental Protection Agency, \\ Office of Research and Development, National Health and Environmental Effects Research Laboratories, Research Triangle Park; \\ and U.S. Environmental Protection Agency, Office of Research and Development, National Exposure Research Laboratories, \\ Research Triangle Park, North Carolina
}

\begin{abstract}
Exposure to fine airborne particulate matter $\left(\mathrm{PM}_{2.5}\right)$ is associated with cardiovascular events and mortality in older and cardiac patients. Potential physiologic effects of in-vehicle, roadside, and ambient $\mathrm{PM}_{2.5}$ were investigated in young, healthy, nonsmoking, male North Carolina Highway Patrol troopers. Nine troopers (age 23 to 30) were monitored on 4 successive days while working a 3 P.M. to midnight shift. Each patrol car was equipped with air-quality monitors. Blood was drawn 14 hours after each shift, and ambulatory monitors recorded the electrocardiogram throughout the shift and until the next morning. Data were analyzed using mixed models. In-vehicle $\mathrm{PM}_{2.5}$ (average of $24 \mu \mathrm{g} / \mathrm{m}^{3}$ ) was associated with decreased lymphocytes $\left(-11 \%\right.$ per $\left.10 \mu \mathrm{g} / \mathrm{m}^{3}\right)$ and increased red blood cell indices ( $1 \%$ mean corpuscular volume), neutrophils $(6 \%)$, C-reactive protein (32\%), von Willebrand factor (12\%), next-morning heart beat cycle length (6\%), next-morning heart rate variability parameters, and ectopic beats throughout the recording (20\%). Controlling for potential confounders had little impact on the effect estimates. The associations of these health endpoints with ambient and roadside $\mathrm{PM}_{2.5}$ were smaller and less significant. The observations in these healthy young men suggest that in-vehicle exposure to $\mathrm{PM}_{2.5}$ may cause pathophysiologic changes that involve inflammation, coagulation, and cardiac rhythm.
\end{abstract}

Keywords: ambulatory electrocardiography; complete blood cell count; vehicle emissions

During the past decade, many epidemiologic studies have reported statistically significant positive correlations between daily mean concentrations of air pollution particulate matter (PM) with an aerodynamic diameter equal to or less than $2.5 \mu \mathrm{m}\left(\mathrm{PM}_{2.5}\right)$ and increased mortality and morbidity attributable to respiratory and cardiovascular causes, as reviewed in the U.S. Environmental Protection Agency Air Quality Criteria for Particulate Matter document (1). Exposure to $\mathrm{PM}_{2.5}$ was positively associated with acute myocardial infarction (2) and with daily deaths for cities throughout the United States, with a linear dose-response relationship extending to very low $\mathrm{PM}_{2.5}$ concentrations (3). Because

(Received in original form October 28, 2003; accepted in final form February 10, 2004) Supported by Environmental Protection Agency cooperative agreements CR824915 and CR-829522 to the University of North Carolina at Chapel Hill, contract 68-D-00-206 to ManTech Environment, and the Swiss National Science Foundation.

Correspondence and requests for reprints should be addressed to Michael Riediker, Institut de Santé au Travail (Institute of Occupational Health Sciences), Rue du Bugnon 19, CH-1005 Lausanne, Switzerland. E-mail: michael.riediker@alumni. ethz.ch

This article has an online supplement, which is accessible from this issue's table of contents online at www.atsjournals.org.

Am I Respir Crit Care Med Vol 169. pp 934-940, 2004

Originally Published in Press as DOI: 10.1164/rccm.200310-14630C on February 12, 2004

Internet address: www.atsjournals.org of the large fraction of the population potentially exposed to PM it has been estimated that 800,000 excess deaths worldwide each year may be attributable to PM (4). Older individuals with underlying cardiac or pulmonary disease appear to be at greatest risk $(5,6)$. Inhalation of PM might result in cardiopulmonary events, which then rapidly trigger increased mortality or morbidity in a small fraction of the population. Two recent studies report associations between elevated PM levels and serious ventricular arrhythmias (7) as well as myocardial infarctions (8). However, the underlying pathophysiologic mechanisms that link PM and cardiopulmonary mortality are still poorly understood.

Heart rate variability (HRV) is influenced by autonomic control mechanisms and helps to identify patients with an increased risk of cardiac mortality (9). Therefore, several panel studies analyzed ambulatory electrocardiogram recordings for PM-associated changes in HRV. In samples of older individuals living in Baltimore (10) and Boston (11) and in cardiac patients (12), increased $\mathrm{PM}_{2.5}$ concentrations were associated with small decreases in HRV. These changes were mostly seen in subjects with preexisting cardiovascular conditions.

PM might also induce lung inflammation, which could cause cardiovascular stress. Low levels of lower respiratory tract inflammation were observed in humans exposed to ambient PM (13). Serum levels of C-reactive protein were increased in relation to ambient PM exposure (8), and acute-phase reactants involved in thrombotic processes, such as fibrinogen, were increased in association with exposure to PM (14).

We investigated the potential health effects of in-vehicle $\mathrm{PM}_{2.5}$ exposure in young, healthy North Carolina State Highway Patrol troopers. Members of this police force spend the majority of their working time in or near their cars and often in heavy traffic. Previous epidemiologic studies had indicated that exposure to particles of vehicular origin might be especially potent with regard to increased mortality $(15,16)$, as well as increased acute cardiovascular morbidity (17). Our hypothesis was that exposure of these healthy young male individuals to $\mathrm{PM}_{2.5}$ from traffic would lead to detectable changes in the autonomic regulation of the heart, as measured by HRV, and that $\mathrm{PM}_{2.5}$ would induce inflammatory responses large enough to be observable in the peripheral blood. Detailed in-vehicle exposure data for $\mathrm{PM}_{2.5}$, its components, gaseous co-pollutants and several organic compounds were collected (18). This article describes the effects of $\mathrm{PM}_{2.5}$. Potentially confounding co-pollutants and activity parameters were included in the analysis. Some of the results of this study have been previously reported in the form of abstracts $(19,20)$.

\section{METHODS}

Ten nonsmoking, male North Carolina State Highway Patrol troopers volunteered to participate in this study in the autumn of 2001 while working a 3 P.M. to midnight shift (but one had to be excluded because of the high frequency of supraventricular ectopic beats and high serum cholesterol levels). The institutional review board of the University of 
North Carolina School of Medicine approved the study. Written consent was obtained from all troopers before their participation in the study. The troopers refrained from alcohol, caffeine, and any medication 24 hours before the start and until the end of their participation.

Two troopers were monitored in parallel each week on 4 consecutive workdays from Monday to Thursday. Venous blood was drawn before the first shift and 10 to 14 hours after each shift. Blood samples were processed immediately for storage and for transport to the laboratory. Parameters analyzed included standard serum chemistry, differential blood cell counts, and inflammation and coagulation markers. The troopers wore ambulatory electrocardiogram monitors throughout the shift and until the next morning. HRV was assessed during controlled resting periods before the shift, after the shift (before going to bed), and the next morning (immediately after awakening). The subjects sat in a quiet room for 20 minutes, and data from the final 10 minutes were used for the HRV analysis. Time-domain parameters included the mean cycle length of R-R intervals for normal beats, the standard deviation of all normal R-R intervals (SDNN) and the percentage of successive normal R-R interval differences greater than $50 \mathrm{~ms}$ (PNN50). The frequency spectrum was divided into low-frequency (LF) power $(0.04$ to $0.15 \mathrm{~Hz})$ and high frequency $(\mathrm{HF})$ power $(0.15$ to $0.40 \mathrm{~Hz})$.

The patrol cars were powered by a gasoline engine and were equipped with air conditioning units. They had a fresh air intake without filtration. Each patrol car was equipped with portable air-quality monitors to measure $\mathrm{PM}_{2.5}$ and other air pollutants during the shift as described earlier (18). $\mathrm{PM}_{2.5}$ was measured by two different methods: particle collection on filters with gravimetric analysis $\left(\mathrm{PM}_{2.5 \text { Mass }}\right)$ and real-time particle mass estimation from light scattering $\left(\mathrm{PM}_{2.5 \mathrm{Lightscatter}}\right.$, most sensitive to particles in the size range of 0.2 to $2.0 \mu \mathrm{m}$ ). These measurements served as an estimate for the troopers' exposure during their work. The route of the car was monitored with a global-positioning system tracking device, and the troopers' activities were obtained from official logs and a diary. Data were also collected simultaneously at a site reflecting urban ambient concentrations $\left(\mathrm{PM}_{2.5 \mathrm{Ambient}}\right)$ and from multiple stationary roadside locations near busy roads in Wake County $\left(\mathrm{PM}_{2.5 \text { Roadside }}\right)$. For these outdoor sites, only gravimetric $\mathrm{PM}_{2.5}$ data are available.

Statistics were calculated using S-Plus 2000 for Windows (Mathsoft Inc., Cambridge, MA). Mixed-effects regression models with restricted maximum likelihood estimation were used to investigate the effects of $\mathrm{PM}_{2.5}$ on HRV and blood parameters (21). The models included a random intercept for each subject and fixed effects for the exposure variables. All parameters as well as the residuals were tested for time trends across the week. The effects of potential confounders were investigated by including them as fixed effects in the models.

Additional details on the methods used to calculate HRV, the processing of the blood samples, and the data treatment procedures are provided in an online supplement.

\section{RESULTS}

\section{Subjects}

Data from a total of nine individual male nonsmoking troopers were used for the analysis, each with 4 consecutive days (10 troopers were monitored, but 1 had to be excluded because of the high frequency of supraventricular ectopic beats and high serum cholesterol levels). The age of the nine subjects (eight white and one black) ranged from 23 to 30 years (average 27.3 years), the average weight from 74 to $102 \mathrm{~kg}$ (average $87 \mathrm{~kg}=$ 192 pounds), the height from 168 to $191 \mathrm{~cm}$ (average $179 \mathrm{~cm}=$ 70.5 inches), and the body mass index from 24 to $31 \mathrm{~kg} / \mathrm{m}^{2}$ (average $27 \mathrm{~kg} / \mathrm{m}^{2}$ ). They were all in excellent physical condition, and all exercised several times per week.

\section{Exposure}

Pollutant levels in the patrol cars of the analyzed troopers were highly variable but were always well below occupational thresh-
TABLE 1. IN-VEHICLE POLLUTANT CONCENTRATIONS DURING THE ANALYZED SHIFTS: MEAN OF ALL SHIFTS, RANGE OF THE SHIFT AVERAGES, AND CORRELATIONS OF THE POLLUTANTS TO FINE PARTICULATE MATTER $\left(\mathrm{PM}_{2.5}\right)$

\begin{tabular}{|c|c|c|c|c|}
\hline & \multicolumn{2}{|c|}{ Concentrations } & \multicolumn{2}{|c|}{$\begin{array}{l}\text { Correlation Coefficients } \\
\text { (Spearman rho) }\end{array}$} \\
\hline & Mean & Range & $\mathrm{PM}_{2.5 \text { Lightscatter }}$ & $\mathrm{PM}_{2.5 \text { Mass }}$ \\
\hline 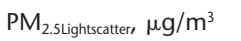 & 24.1 & $4.5-54.4$ & 1.00 & $0.71^{\dagger}$ \\
\hline $\mathrm{PM}_{2.5 \text { Mass, }} \mu \mathrm{g} / \mathrm{m}^{3}$ & 23.0 & $7.1-38.7$ & $0.71^{\dagger}$ & 1.00 \\
\hline $\mathrm{PM}_{2.5 \text { Ambient }} \mu \mathrm{g} / \mathrm{m}^{3}$ & 32.3 & $9.9-68.9$ & $0.67^{\dagger}$ & $0.63^{\dagger}$ \\
\hline $\mathrm{PM}_{2.5 \text { Roadside, }} \mu \mathrm{g} / \mathrm{m}^{3}$ & 32.1 & $8.9-62.2$ & $0.65^{\dagger}$ & $0.58^{\dagger}$ \\
\hline Ozone, ppb & 12.4 & $-4.7^{\star}-57.6$ & -0.21 & 0.23 \\
\hline $\mathrm{CO}, \mathrm{ppm}$ & 2.6 & $0.9-5.9$ & $0.53^{\dagger}$ & $0.55^{\dagger}$ \\
\hline $\mathrm{NO}_{2}, \mathrm{ppb}$ & 35 & $1.6-213$ & -0.30 & 0.06 \\
\hline Relative humidity, \% & 36 & $25-46$ & $0.40^{\dagger}$ & $0.33^{\dagger}$ \\
\hline Temperature, ${ }^{\circ} \mathrm{C}$ & 25.6 & $20.3-29.1$ & 0.17 & 0.15 \\
\hline
\end{tabular}

Definition of abbreviations: $\mathrm{ppb}=$ parts per billion; $\mathrm{PM}_{2.5}=$ particulate matter with an aerodynamic diameter equal to or less than $2.5 \mu \mathrm{m}$.

After blank correction.

† Significant correlation with $\mathrm{p}<0.05$.

old limits values (Table 1). Individual volatile organic compound levels (hydrocarbons and aldehydes) inside the investigated cars were in the parts per billion range. In-vehicle $\mathrm{PM}_{2.5}$ was $24 \%$ lower than ambient and roadside concentrations, whereas in-vehicle $\mathrm{CO}$, $\mathrm{NO}_{2}$, aldehydes, hydrocarbons, and some metals were elevated. On average, troopers spent $35 \%$ of their shift away from the car, mostly inside buildings (office, jail, hospitals, or for dinner). None of the investigated exposure parameters showed a time trend for increasing or decreasing concentrations throughout the weekdays. A detailed description of pollutants measured inside the vehicles, at the roadside, and at the fixed ambient site is published elsewhere (18).

\section{Changes in Cardiac Parameters}

Most HRV parameters increased significantly from the start of the shift in the afternoon until midnight, and SDNN (in the time domain) and total frequency power (in the frequency domain) were further increased in the morning after awakening (see Table E1 in the online supplement). None of the investigated cardiac parameters showed a time-trend throughout the weekdays.

The associations between the $\mathrm{PM}_{2.5}$ concentrations inside the cars (averages of the 9-hour shifts) and the HRV parameters (at midnight and in the morning after the shift) are shown in Table 2. $\mathrm{PM}_{2.5 \mathrm{Lightscatter}}$ during the shift was significantly positively associated with all time domain parameters (PNN50, SDNN, and mean cycle length) as well as with HF power and the power ratio $\mathrm{LF} / \mathrm{HF}$ on the morning after the shift. The effect estimates (slopes) for $\mathrm{PM}_{2.5 \mathrm{Mass}}$ were similar; however, these associations had a larger uncertainty, and only the effect estimate for mean cycle length reached significance (Figure E1 in the online supplement shows exposure-response plots for a selection of the significant associations of health parameters to the $\mathrm{PM}_{2.5}$ measures).

The number of ectopic beats throughout the work shift and during the contiguous night was low. Most supraventricular ectopic beats occurred during the sleep, whereas the ventricular ectopic beats were most frequent in the late evening and around wake-up. Both ventricular and supraventricular ectopic beats were strongly increased in association with $\mathrm{PM}_{2.5 \text { Lightscatter }}$ but not with $\mathrm{PM}_{2.5 \mathrm{Mass}}$ (Table 2). 
TABLE 2. HEART RATE VARIABILITY AND ECTOPY PARAMETERS AND THEIR ASSOCIATION WITH THE IN-VEHICLE FINE PARTICULATE MATTER $\left(\mathrm{PM}_{2.5}\right)$

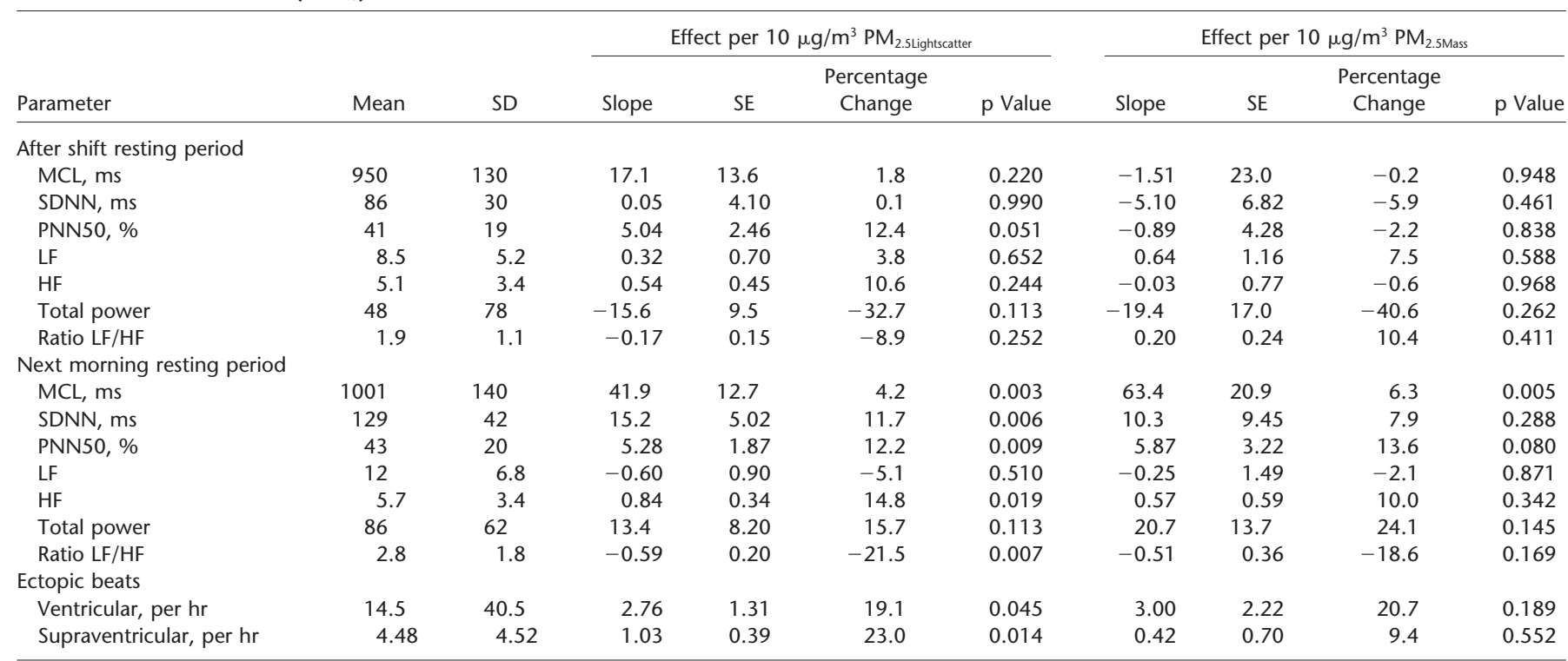

Definition of abbreviations: $\mathrm{HF}=$ high frequency; $\mathrm{LF}=$ low frequency; $\mathrm{MCL}=$ mean cycle length; PM = particulate matter; $\mathrm{PNN50}=$ percentage of successive norma R-R interval differences greater than $50 \mathrm{~ms} ; \mathrm{SDNN}=\mathrm{SD}$ of all normal R-R intervals.

Effect estimates are given in absolute values (slopes with SE) and as percent change relative to the mean. $p$ Values $<0.05$ are significant.

\section{Changes in Vascular Components}

Standard serum chemistries were within the normal range for all subjects studied. Only serum osmolality was slightly elevated with an average of $296 \mathrm{mOsm} / \mathrm{kg}$ (SD of $3.1 \mathrm{mOsm} / \mathrm{kg}$ ). None of the investigated vascular components showed a time-trend throughout the weekdays. $\mathrm{PM}_{2.5}$ concentrations inside the cars were significantly associated with changes in parameters of the blood that was collected approximately 14 hours after the shift (Table 3). In contrast with the cardiac measurements, vascular components were more often significantly associated with $\mathrm{PM}_{2.5 \mathrm{Mass}}$ than with $\mathrm{PM}_{2.5 \text { Lightscatter }}$.

Small but significant $(p=0.0002)$ changes were seen for red blood cell volume $(\mathrm{MCV})$ in association with $\mathrm{PM}_{2.5 \text { Lightscatter }}$ This was true for each individual trooper (shown in Figure E1D in the online supplement) as well as for the group as a whole. MCV was also significantly associated with $\mathrm{PM}_{2.5 \text { Mass }}$. The potential effect of osmolality on MCV and MCHC was assessed by standardizing them to the average osmolality (MCV multiplied by the osmolality of the sample and divided by the average osmolality; the inverse for MCHC). This standardization did not change the effect estimates listed in Table 3 but did increase the statistical significance.

\section{Associations with Ambient and Roadside $\mathrm{PM}_{2.5}$ Concentrations}

Figure 1 summarizes the associations between time-domain HRV parameters, ectopic beats, and selected vascular compo-

TABLE 3. BLOOD PARAMETERS (MEAN AND SD) AND THEIR ASSOCIATION WITH THE IN-VEHICLE FINE PARTICULATE MATTER $\left(\mathrm{PM}_{2.5}\right)$ CONCENTRATIONS

\begin{tabular}{|c|c|c|c|c|c|c|c|c|c|c|}
\hline \multirow[b]{2}{*}{ Blood Parameter } & \multirow[b]{2}{*}{ Mean } & \multirow[b]{2}{*}{ SD } & \multicolumn{4}{|c|}{ Effect per $10 \mu \mathrm{g} / \mathrm{m}^{3} \mathrm{PM}_{2.5 \text { Lightscatter }}$} & \multicolumn{4}{|c|}{ Effect per $10 \mu \mathrm{g} / \mathrm{m}^{3} \mathrm{PM}_{2.5 \text { Mass }}$} \\
\hline & & & Slope & SE & \% Change & $\mathrm{p}$ Value & Slope & SE & $\%$ Change & p Value \\
\hline Uric acid, serum, mg/dl & 6.2 & 1.1 & 0.07 & 0.12 & 1.2 & 0.555 & 0.38 & 0.19 & 6.1 & 0.055 \\
\hline Hematocrit, \% & 45 & 3.0 & 0.70 & 0.27 & 1.5 & 0.014 & 0.29 & 0.48 & 0.6 & 0.554 \\
\hline $\mathrm{MCV}, \mathrm{fL}$ & 88 & 2.9 & 0.85 & 0.19 & 1.0 & 0.0002 & 0.78 & 0.37 & 0.9 & 0.045 \\
\hline $\mathrm{MCH}, \mathrm{pg}$ & 30 & 0.9 & 0.10 & 0.08 & 0.3 & 0.242 & 0.28 & 0.13 & 0.9 & 0.033 \\
\hline $\mathrm{MCHC}, \mathrm{g} / \mathrm{dl}$ & 34 & 0.7 & -0.19 & 0.08 & -0.6 & 0.032 & -0.22 & 0.14 & -0.7 & 0.129 \\
\hline Neutrophils, \% & 58 & 8.5 & 1.85 & 1.00 & 3.2 & 0.077 & 3.56 & 1.61 & 6.2 & 0.036 \\
\hline Lymphocytes, \% & 31 & 7.4 & -1.71 & 0.87 & -5.5 & 0.059 & -3.29 & 1.39 & -10.5 & 0.025 \\
\hline Lymphocyte count, $10^{3} / \mu \mathrm{l}$ & 1.6 & 0.4 & -0.05 & 0.04 & -3.0 & 0.281 & -0.13 & 0.07 & -8.4 & 0.063 \\
\hline C-reactive protein, $\mathrm{mg} / \mathrm{L}$ & 1.0 & 1.2 & 0.21 & 0.08 & 21.1 & 0.013 & 0.32 & 0.13 & 31.9 & 0.023 \\
\hline Plasminogen, IU/ml & 1.7 & 1.7 & 0.27 & 0.22 & 15.9 & 0.221 & 0.67 & 0.36 & 39.6 & 0.073 \\
\hline von Willebrand factor, \% & 153 & 37 & 5.50 & 4.60 & 3.6 & 0.242 & 18.0 & 7.13 & 11.8 & 0.018 \\
\hline
\end{tabular}

Definition of abbreviations: $\mathrm{MCH}=$ mean red blood cell volume; $\mathrm{MCHC}=$ mean red blood cell hemoglobin; $\mathrm{MCV}=$ mean red blood cell hemoglobin concentration; $\mathrm{PM}=$ particulate matter.

Only parameters with $p<0.1$ are listed ( $p<0.05$ are significant). Blood was sampled 14 hours after the shift ended. Effect estimates are in absolute values (slopes with $\mathrm{SE}$ ) and as a percentage change relative to the mean. 
A

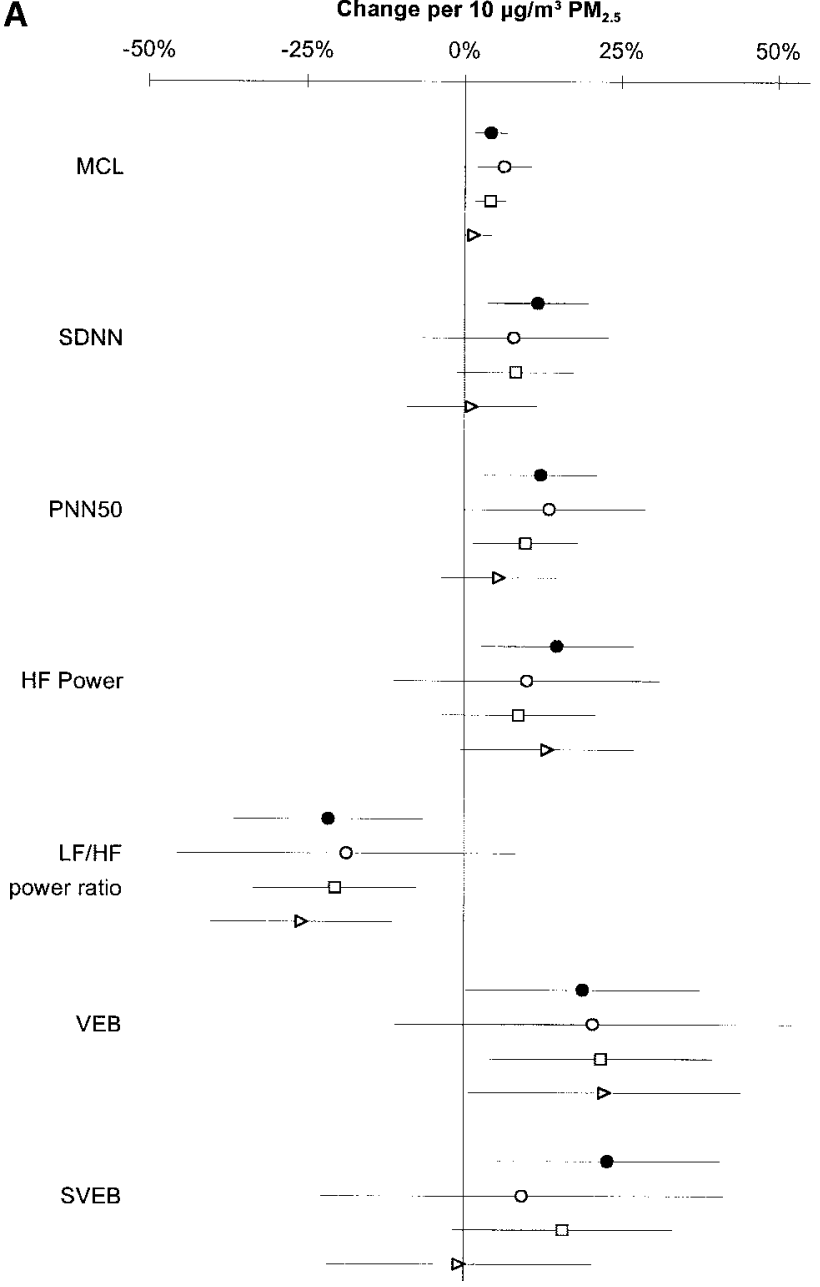

B

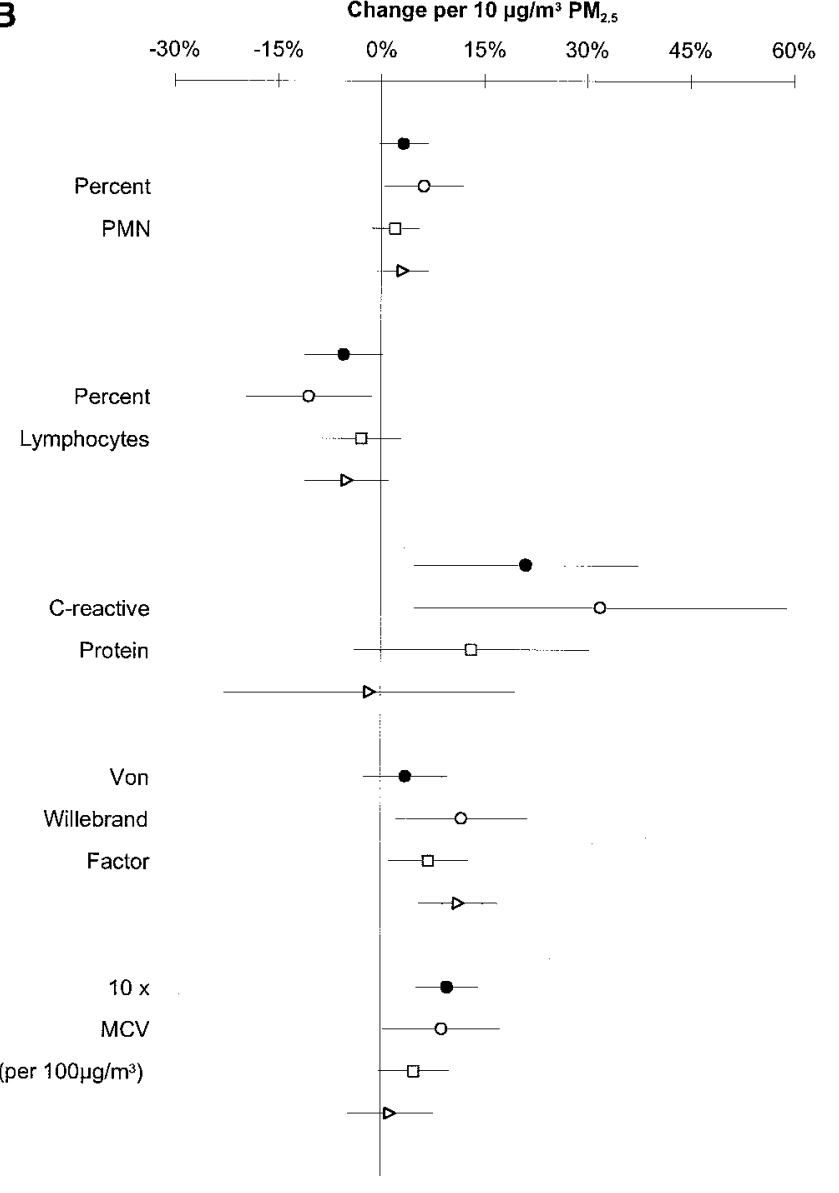

Figure 1. Selected heart rhythm $(A)$ and blood $(B)$ parameters. Comparison of fine particulate matter $\left(\mathrm{PM}_{2.5}\right)$ effect estimates for the two in-vehicle

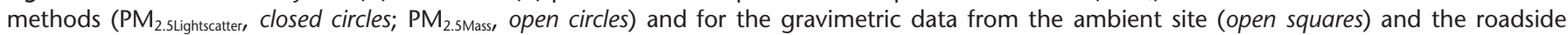
locations (open triangles). Lines indicate the $95 \%$ confidence intervals of the effect estimates. The effect estimates for MCV were multiplied by 10 to better fit the scale.

nents; and PM measured in-vehicle, at the roadside, and from fixed-site community monitors. The most consistent effect estimates across all $\mathrm{PM}_{2.5}$ measurements were seen with ventricular ectopic beats. Effect estimates for roadside $\mathrm{PM}_{2.5}$ and several effect estimates for ambient $\mathrm{PM}_{2.5}$ tended to be smaller than the comparable in-vehicle effect estimates. Roadside mass resulted for most parameters in the smallest effect estimates. For each parameter, in-vehicle $\mathrm{PM}_{2.5 \text { Mass }}$ had the widest confidence intervals compared with all other $\mathrm{PM}_{2.5}$ measures, whereas $\mathrm{PM}_{2.5 \text { Roadside }}$ had wider confidence intervals than $\mathrm{PM}_{2.5 \text { Ambient }}$.

\section{Potential Confounders}

The potentially confounding effects of $\mathrm{CO}, \mathrm{NO}_{2}$, and relative humidity were investigated by including them in bivariate models with $\mathrm{PM}_{2.5}$. These co-pollutants were to some extent correlated to $\mathrm{PM}_{2.5}$ (Table 1), which makes them potential confounders of $\mathrm{PM}_{2.5}$ effects. The procedure led to minimal changes in most effect estimates for the HRV parameters (see Figure E2 in the online supplement). However, for ventricular ectopic beats, including $\mathrm{NO}_{2}$ and relative humidity broadened the $95 \%$ confidence intervals and made the effect estimate for $\mathrm{PM}_{2.5 \text { Lightscatter }}$ nonsignificant. The same relationship was observed with $\mathrm{CO}$ and supraventricular ectopic beats. In both cases, the effect estimates (slopes) themselves were little changed. None of the effect estimates for $\mathrm{NO}_{2}, \mathrm{CO}$, or relative humidity were significant in any of these models.

Controlling the blood parameters for the same confounders did not reduce the effect estimates for the $\mathrm{PM}_{2.5}$ associations with $\mathrm{MCV}$, von Willebrand factor, and C-reactive protein. However, for $\mathrm{CO}$ and leukocyte percentages (percentage of neutrophils and percentage of lymphocytes), the bivariate models showed a clear drop in the $\mathrm{PM}_{2.5}$ effect estimates (especially for $\mathrm{PM}_{2.5 \text { Lightscatter }}$ ), and the $95 \%$ confidence intervals were broadened to include zero. None of the effect estimates for $\mathrm{NO}_{2}, \mathrm{CO}$, or relative humidity were significant in any of these models.

The potential influence of stress was controlled by including the number of accidents during the shift, the number of citations issued, "other" activities, and the total number of law-enforcement activities. Controlling the HRV parameters for these factors had virtually no effect on either the effect estimates or the confidence intervals. However, significant effect estimates for the association between PNN50 and $\mathrm{PM}_{2.5 \text { Lightscatter }}$ resulted after controlling for the number of accidents (slope of $5.68 \pm 2.56$, $\mathrm{p}=0.04)$, "other" activities $(6.20 \pm 2.24, \mathrm{p}=0.01)$, and total number of law enforcement activities $(5.54 \pm 2.56, \mathrm{p}=0.04)$. 


\section{DISCUSSION}

This study investigated the effects of relatively low levels of $\mathrm{PM}_{2.5}$ exposure inside vehicles in a selected group of young, healthy, nonsmoking, fit, male highway patrol troopers. The troopers showed significant and strong increases of HRV, ectopic beats, blood inflammatory and coagulation markers, and MCV in association with the in-vehicle exposure to $\mathrm{PM}_{2.5}$. These novel findings could be helpful in better understanding the pathophysiologic processes subsequent to $\mathrm{PM}_{2.5}$ exposure that can lead in susceptible populations to increases in cardiovascular morbidity and mortality.

Normal values for all baseline blood work attest to the excellent general health of the troopers. The fitness of the troopers is evidenced by their average body mass index of 27 and their low resting pulse (approximately 60 beats per minute). The slightly elevated serum osmolality (average of $296 \mathrm{mOsm} / \mathrm{kg}$ ) possibly reflects slight dehydration secondary to inadequate fluid replacement during the work shift. Overall, these troopers represent a clinical subgroup that appears to be at very low risk for cardiac or other adverse health conditions.

$\mathrm{PM}_{2.5}$ was relatively low inside the cars compared with the 24-hour National Ambient Air Quality Standard for $\mathrm{PM}_{2.5}$ of $65 \mu \mathrm{g} / \mathrm{m}^{3}$ and mostly in the "green" and "yellow" range of the air quality index (i.e., below $40 \mu \mathrm{g} / \mathrm{m}^{3} \mathrm{PM}_{2.5}$ ). $\mathrm{PM}_{2.5}$ was measured gravimetrically and also estimated with a light-scattering device. The two methods resulted in almost identical averages and were highly correlated (Table 1 ). However, the $\mathrm{PM}_{2.5}$ levels estimated by light scattering had a larger variability, as reflected by the interquartile range. This is consistent with earlier studies comparing these two devices (22). Gravimetric particle measures are strongly influenced by large particles, whereas the lightscattering device estimates are more influenced by particle numbers. Inside the patrol cars, the two methods appear to reflect these differences: $\mathrm{PM}_{2.5 \text { Mass }}$ represents exposure to some coarse mode material from suspended road dust as well as to ambient accumulation mode particles, whereas $\mathrm{PM}_{2.5 \mathrm{Lightscatter}}$ represents ambient particles and fresh combustion particles, which occur in high numbers in the smaller accumulation size range.

Inflammatory markers in the peripheral blood collected 10 to 14 hours after the work shift were associated with the $\mathrm{PM}_{2.5 \mathrm{Mass}}$ concentration in the cars. von Willebrand factor, a marker for endothelial activation and thrombosis (23), the inflammatory marker C-reactive protein, and the percentage of neutrophils were increased, whereas the percentage of lymphocytes was decreased. These data suggest that PM exposure causes slight vascular inflammation. It is possible that this inflammation was restricted to the peripheral lung, where a large proportion of fine particles is deposited $(24,25)$. Our findings suggesting $\mathrm{PM}_{2.5}$ exposure to cause inflammatory processes is consistent with other studies, which reported elevated C-reactive protein levels (8) and inflammatory cell numbers (13) as a consequence of $\mathrm{PM}_{2.5}$ exposure.

The inflammatory blood markers for which we observed changes have been previously linked to increased morbidity. A recent prospective study showed increased von Willebrand factor to be associated with an increased risk of coronary heart disease and nonfatal myocardial infarction (26). Increased C-reactive protein levels were also associated to cardiovascular diseases (27) and coronary calcification (28). It was reported that C-reactive protein was an even better long-term predictor for cardiovascular events than cholesterol (29), although the predictive value of increased levels of C-reactive protein for these diseases is still disputed (30). The low concentration of C-reactive protein in the serum of the troopers (average of approximately $1 \mathrm{mg} / \mathrm{L}$ ) suggests a relatively low cardiovascular risk (29). Nevertheless, the consequences of several years of daily exposure to in-vehicle pollutants for the development of arteriosclerosis, particularly if these pollutants increase markers of systemic inflammation, remain unclear.

The various inflammatory markers differed in the strength and significance of their association to particle concentrations at the various locations and in the effects of potential confounders on the association. These differences could reflect several at least partly independent inflammatory processes in response to the particles or their components: The association between the inflammatory markers and $\mathrm{PM}_{2.5 \mathrm{Mass}}$ was much tighter compared with $\mathrm{PM}_{2.5 \text { Lightscatter }}$ Consequently, the larger accumulation size particles might be more important for the inflammatory process observed. There was no association of neutrophils, lymphocytes, and C-reactive protein to roadside and ambient particle concentrations, and $\mathrm{PM}_{25 \mathrm{Mass}}$ lost significance in the model with $\mathrm{CO}$ (whereas CO had no significant effects in this model). This can be explained by two possibilities: (1) Other combustion products (and not solely particle mass) might be important for the leukocyte response as well, or (2) mostly traffic-related particles (with $\mathrm{CO}$ as an indicator for traffic) were causing the response. Future analyses of co-pollutants and particle composition might answer the question, whether particles from traffic sources might have caused this strong inflammatory response.

The increase of the red blood cell volume MCV associated with increasing $\mathrm{PM}_{2.5}$ could not be explained by decreased serum osmolality and therefore could be a consequence of particle components or inflammatory mediators interfering with the volume regulatory ion channels and/or pumps in the erythrocytes (31). These changes in MCV also raise a question about potential effects of $\mathrm{PM}_{2.5}$ exposure on ion channels and/or pumps in other cell types. An earlier study (32) found PM-associated changes in red blood cell count, hematocrit, and hemoglobin concentration. No results were reported for MCV. They proposed peripheral sequestration of red cells as an explanation. However, our results favor a mechanism that affects the volume of red blood cells.

The troopers' resting HRV after the shift (at midnight before going to bed) was influenced very little by the $\mathrm{PM}_{2.5}$ exposure during the shift. Instead, the HRV changes across the shift seemed to reflect mostly a diurnal pattern and a normal physiological change from daytime to late evening. The changes are in a range similar to those observed for preshift and postshift HRV of emergency physicians on a night shift schedule (33), in steel workers on evening shift (34), and between sleep and work in nurses (35). Only PNN50 showed some association with $\mathrm{PM}_{2.5 \text { Lightscatter }}(\mathrm{p}=0.051$, significant after controlling for some of the activity parameters). This might indicate that some HRV changes had already started at midnight, although the changes were mostly too small to be detected within the noise from the daily activities and the daytime variation.

The HRV parameters were highest in the morning on arising. This is in contrast to a study of HRV in nurses (35), which reported that HRV at the time of awakening was equal to daytime levels. The mixed model analysis of the trooper's data suggests that this increase of HRV was mostly a consequence of the preceding in-vehicle $\mathrm{PM}_{2.5}$ exposure and not simply a diurnal pattern. Furthermore, the increase in the HRV from the afternoon to the next morning was similar to that reported for steel workers (34), who (like the troopers) have occupational exposure to $\mathrm{PM}_{2.5}$ and physically demanding work.

This study shows a strong and consistent increase of HRV in association with $\mathrm{PM}_{2.5}$. The pattern of HRV-responses suggests increased vagal activity, that is, the involvement of the nervous system in the response to PM. Studies about the interactions 
between the immune system and the brain report local inflammatory reactions to increase the vagal sensory input to the brain, which again can result in increased vagal output (as reviewed in 36). Our results indicating mild inflammatory processes in the lungs and increased vagal output to the heart would be in agreement with these models. However, our HRV results are in contrast to earlier observational studies in panels of older individuals $(10,11)$, in older cardiac patients $(12)$, and in middle-aged boilermakers (37), as well as controlled exposure experiments in older subjects (38), in whom a small decrease of HRV in association with $\mathrm{PM}_{2.5}$ exposure was observed (the boilermakers showed a very small increase in SDNN in association with concentrations of some metallic components of the particles) (39). These opposing results might be caused by differences in age, cardiovascular fitness, or prevalence of cardiovascular disease. In one study with older subjects (10), only the group with cardiovascular conditions showed a decreased SDNN in response to the $\mathrm{PM}_{2.5}$ exposure of the same day. Controlled exposure to residual oil fly ash caused decreased SDNN as an immediate reaction in rats with prior myocardial infarction, but not in healthy control rats (40). Age per se might be important as well because the subjects from the previously cited controlled exposure study (38) had a mean age of 67 years. Vagal function is reduced in the aged and in clinical populations such as diabetics (41-43). This can lead to differences in the heart's response to the vagal output because different competitive vagal pathways are involved in the autonomic control of the heart rate (44). The troopers were young and physically fit and were with a well-conditioned and responsive cardiovascular system. Consequently, our results might reflect a "healthy" physiologic response to PM as compared with the older subjects, cardiac patients, and the middle-aged boilermakers who have a reduced cardiovascular dynamism and changed vagal function.

Premature supraventricular ectopic beats increased $23 \%$, and ventricular ectopic beats increased $19 \%$ for each $10 \mu \mathrm{g} / \mathrm{m}^{3}$ in-

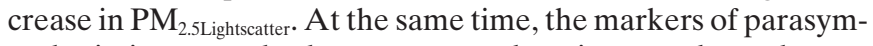
pathetic input to the heart suggested an increased vagal tone: the $\mathrm{LF} / \mathrm{HF}$ ratio was decreased by $21 \%$, and HF, PNN50, and SDNN were increased by over $10 \%$. These findings implicate a vagal mechanism of the premature ectopic beats. Fluctuations in autonomic tone have been reported to be associated with the triggering of atrial arrhythmias (45) and may thus offer insight into the mechanism of arrhythmias associated with air pollution. The observation that the relationship was strongest with the $\mathrm{PM}_{2.5 \text { Lightscatter }}$ indicates that fine particles are more likely to mediate the cardiac responses.

In cardiac patients, increased HRV and heart rate were observed in the period before the onset of postoperative atrial fibrillation, which suggested vagal resurgence competing with sympathetic activity to be the primary mechanism responsible for the triggering of atrial fibrillation (46). The consequences of an increased vagal tone in healthy young people are not well defined. Apparently, the increase in (benign) ectopic beats might be related to the increase in vagal tone. It is unclear whether this poses any risk to the troopers, although it does represent a $\mathrm{PM}_{2.5}$-induced alteration of normal homeostatic control.

\section{Conclusions}

In-vehicle $\mathrm{PM}_{2.5}$ exposure of healthy, young, nonsmoking, male North Carolina State Highway Patrol troopers was associated with significant increases in vagal activity, as reflected by the changes in HRV, with increased number of ectopic beats and with increases in MCV and in peripheral blood inflammatory and coagulation markers. These effects were observed a few hours after the exposure and suggest two general pathophysio- logic pathways subsequent to $\mathrm{PM}_{2.5}$ deposition in the peripheral lungs: (1) via proinflammatory and prothrombotic blood changes and (2) via changes of cardiac autonomic control mechanisms. The changes observed do not seem desirable and suggest that exposure to in-vehicle $\mathrm{PM}_{2.5}$ should be minimized.

Conflict of Interest Statement: M.R. has no declared conflict of interest; W.E.C. has no declared conflict of interest; T.R.G. has no declared conflict of interest; M.C.H. has no declared conflict of interest; P.A.B. has no declared conflict of interest; L.N. has no declared conflict of interest; R.W.W. has no declared conflict of interest; R.B.D. has no declared conflict of interest.

\section{References}

1. US-EPA. Air quality criteria for particulate matter EPA/600/P-95/001cf. Research Triangle Park, NC: National Center for Environmental Assessment, Office of Research and Development, U.S. Environmental Protection Agency; 1996.

2. Peters A, Dockery DW, Muller JE, Mittleman MA. Increased particulate air pollution and the triggering of myocardial infarction. Circulation 2001;103:2810-2815.

3. Schwartz J, Laden F, Zanobetti A. The concentration-response relation between $\operatorname{PM}(2.5)$ and daily deaths. Environ Health Perspect 2002; 110:1025-1029.

4. World Health Organization. The world health report: reducing risks, promoting healthy life [accessed July 17, 2003]. Available from: http:// www.who.int/whr/en/. Geneva, Switzerland: World Health Organization; 2002.

5. Schwartz J. Air pollution and hospital admissions for heart disease in eight US counties. Epidemiology 1999;10:17-22.

6. De Leon SF, Thurston GD, Ito K. Contribution of respiratory disease to nonrespiratory mortality associations with air pollution. Am J Respir Crit Care Med 2003;167:1117-1123.

7. Peters A, Liu E, Verrier RL, Schwartz J, Gold DR, Mittleman M, Baliff $\mathrm{J}$, Oh JA, Allen G, Monahan K, et al. Air pollution and incidence of cardiac arrhythmia. Epidemiology 2000;11:11-17.

8. Peters A, Frohlich M, Doring A, Immervoll T, Wichmann HE, Hutchinson WL, Pepys MB, Koenig W. Particulate air pollution is associated with an acute phase response in men: results from the MONICAAugsburg Study. Eur Heart J 2001;22:1198-1204.

9. Lombardi F. Clinical implications of present physiological understanding of HRV components. Card Electrophysiol Rev 2002;6:245-249.

10. Liao D, Creason J, Shy C, Williams R, Watts R, Zweidinger R. Daily variation of particulate air pollution and poor cardiac autonomic control in the elderly. Environ Health Perspect 1999;107:521-525.

11. Gold D, Litonjua A, Schwartz J, Lovett E, Larson A, Nearing B, Allen G, Verrier M, Cherry R, Verrier R. Ambient pollution and heart rate variability. Circulation 2000;101:1267-1273.

12. Pope CA III, Verrier RL, Lovett EG, Larson AC, Raizenne ME, Kanner RE, Schwartz J, Villegas GM, Gold DR, Dockery DW. Heart rate variability associated with particulate air pollution. Am Heart J 1999; 138:890-899.

13. Ghio AJ, Kim C, Devlin RB. Concentrated ambient air particles induce mild pulmonary inflammation in healthy human volunteers. $A m J$ Respir Crit Care Med 2000;162:981-988.

14. Pekkanen J, Brunner EJ, Anderson HR, Tiittanen P, Atkinson RW. Daily concentrations of air pollution and plasma fibrinogen in London. Occup Environ Med 2000;57:818-822.

15. Bigert C, Gustavsson P, Hallqvist J, Hogstedt C, Lewne M, Plato N, Reuterwall C, Scheele P. Myocardial infarction among professional drivers. Epidemiology 2003;14:333-339.

16. Laden F, Neas LM, Dockery DW, Schwartz J. Association of fine particulate matter from different sources with daily mortality in six US cities. Environ Health Perspect 2000;108:941-947.

17. Janssen NA, Schwartz J, Zanobetti A, Suh HH. Air conditioning and source-specific particles as modifiers of the effect of PM(10) on hospital admissions for heart and lung disease. Environ Health Perspect 2002; 110:43-49.

18. Riediker M, Williams R, Devlin R, Griggs T, Bromberg P. Exposure to particulate matter, volatile organic compounds and other air pollutants inside patrol cars. Environ Sci Technol 2003;37:2084-2093.

19. Riediker M, Devlin R, Griggs T, Cascio W, Herbst M, Williams R, McCorquodale S, Bromberg P. Changes in health parameters observed in $\mathrm{NC}$ patrol troopers exposed to PM and air toxics (COPP-study). Epidemiology 2002;13:108.

20. Riediker M, Bromberg PA, Cascio WA, Griggs T, Herbst M, Williams RW, Neas LM, Devlin RB. PM2.5 exposure changes heart rate vari- 
ability (HRV) and blood parameters in state highway patrol troopers [abstract]. Am J Respir Crit Care Med 2003;167:A332.

21. Pinheiro JC, Bates DM. Mixed-effects models in S and S-PLUS. Heidelberg, Germany: Springer Verlag; 2000.

22. Rea AW, Zufall MJ, Williams RW, Sheldon L, Howard-Reed C. The influence of human activity patterns on personal PM exposure: a comparative analysis of filter-based and continuous particle measurements. J Air Waste Manage Assoc 2001:51:1271-1279.

23. Conway DS, Pearce LA, Chin BS, Hart RG, Lip GY. Plasma von Willebrand factor and soluble p-selectin as indices of endothelial damage and platelet activation in 1,321 patients with nonvalvular atrial fibrillation: relationship to stroke risk factors. Circulation 2002;106:1962-1967.

24. Kim CS, Hu SC, DeWitt P, Gerrity TR. Assessment of regional deposition of inhaled particles in human lungs by serial bolus delivery method. J Appl Physiol 1996;81:2203-2213.

25. Kim CS, Jaques PA. Respiratory dose of inhaled ultrafine particles in healthy adults. Phil $\operatorname{Tr} R$ Soc $S$ - $A$ 2000;358:2693-2705.

26. Whincup PH, Danesh J, Walker M, Lennon L, Thomson A, Appleby P, Rumley A, Lowe GD. von Willebrand factor and coronary heart disease: prospective study and meta-analysis. Eur Heart $J$ 2002;23: 1764-1770.

27. Ridker PM. High-sensitivity C-reactive protein: potential adjunct for global risk assessment in the primary prevention of cardiovascular disease. Circulation 2001;103:1813-1818.

28. Wang TJ, Larson MG, Levy D, Benjamin EJ, Kupka MJ, Manning WJ, Clouse ME, D'Agostino RB, Wilson PW, O'Donnell CJ. C-reactive protein is associated with subclinical epicardial coronary calcification in men and women: the Framingham Heart Study. Circulation 2002; 106:1189-1191.

29. Ridker PM, Rifai N, Rose L, Buring JE, Cook NR. Comparison of C-reactive protein and low-density lipoprotein cholesterol levels in the prediction of first cardiovascular events. N Engl J Med 2002;347: $1557-1565$

30. Kushner I, Sehgal AR. Is high-sensitivity C-reactive protein an effective screening test for cardiovascular risk? Arch Intern Med 2002;162: 867-869.

31. Kowluru R, Bitensky MW, Kowluru A, Dembo M, Keaton PA, Buican T. Reversible sodium pump defect and swelling in the diabetic rat erythrocyte: effects on filterability and implications for microangiopathy. Proc Natl Acad Sci USA 1989;86:3327-3331.

32. Seaton A, Soutar A, Crawford V, Elton R, McNerlan S, Cherrie J, Watt M, Agius R, Stout R. Particulate air pollution and the blood. Thorax 1999;54:1027-1032.
33. Adams SL, Roxe DM, Weiss J, Zhang F, Rosenthal JE. Ambulatory blood pressure and Holter monitoring of emergency physicians before, during, and after a night shift. Acad Emerg Med 1998;5:71-77.

34. Furlan R, Barbic F, Piazza S, Tinelli M, Seghizzi P, Malliani A. Modifications of cardiac autonomic profile associated with a shift schedule of work. Circulation 2000;102:1912-1916.

35. Ito H, Nozaki M, Maruyama T, Kaji Y, Tsuda Y. Shift work modifies the circadian patterns of heart rate variability in nurses. Int J Cardiol 2001:79:231-236.

36. Maier SF, Watkins LR. Cytokines for psychologists: implications of bidirectional immune-to-brain communication for understanding behavior, mood and cognition. Psychol Rev 1998;105:83-107.

37. Magari SR, Hauser R, Schwartz J, Williams PL, Smith TJ, Christiani DC. Association of heart rate variability with occupational and environmental exposure to particulate air pollution. Circulation 2001;104: 986-991.

38. Devlin R, Ghio A, Kehrl H, Sanders G, Cascio W. Elderly humans exposed to concentrated air pollution particles have decreased heart rate variability. Eur Respir J Suppl 2003;40:s76-s80.

39. Magari SR, Schwartz J, Williams PL, Hauser R, Smith TJ, Christiani DC. The association of particulate air metal concentrations with heart rate variability. Environ Health Perspect 2002;110:875-880.

40. Wellenius GA, Saldiva PH, Batalha JR, Krishna Murthy GG, Coull BA, Verrier RL, Godleski JJ. Electrocardiographic changes during exposure to residual oil fly ash (ROFA) particles in a rat model of myocardial infarction. Toxicol Sci 2002;66:327-335.

41. Wieling W, van Brederode JF, de Rijk LG, Borst C, Dunning AJ. Reflex control of heart rate in normal subjects in relation to age: a data base for cardiac vagal neuropathy. Diabetologia 1982;22:163-166.

42. Weise F, Heydenreich F. Age-related changes of heart rate power spectra in a diabetic man during orthostasis. Diabetes Res Clin Pract 1991;11: 23-32.

43. De Meersman RE. Aging as a modulator of respiratory sinus arrhythmia J Gerontol 1993;48:B74-B78.

44. Porges SW. Orienting in a defensive world: mammalian modifications of our evolutionary heritage: a polyvagal theory. Psychophysiology 1995;32:301-318.

45. Zimmermann M, Kalusche D. Fluctuation in autonomic tone is a major determinant of sustained atrial arrhythmias in patients with focal ectopy originating from the pulmonary veins. J Cardiovasc Electrophysiol 2001;12:285-291.

46. Amar D, Zhang H, Miodownik S, Kadish AH. Competing autonomic mechanisms precede the onset of postoperative atrial fibrillation. J Am Coll Cardiol 2003;42:1262-1268. 